\title{
Solution of internal erosion equations by asymptotic expansion
}

\author{
F. Yakhlef ${ }^{1}$, A. Khamlichi ${ }^{1}$, M. Bezzazi ${ }^{1}$, M.A. Parron Vera ${ }^{2}$, P. Dubujet ${ }^{3}$ \\ ${ }^{1}$ Laboratory MAS, Faculty of Sciences, Tetouan, Morocco \\ ${ }^{2}$ High Polytechnic School of Algeciras, University of Cadiz, Spain \\ ${ }^{3}$ Laboratory LTDS, University of Lyon, Saint-Etienne, France
}

\begin{abstract}
One dimensional coupled soil internal erosion and consolidation equations are considered in this work for the special case of well determined sand and clay mixtures with a small proportion of clay phase. An enhanced modelling of the effect of erosion on elastic soil behavior was introduced through damage mechanics concepts. A modified erosion law was proposed. The erosion phenomenon taking place inside the soil was shown to act like a perturbation affecting the classical soil consolidation equation. This interpretation has enabled considering an asymptotic expansion of the coupled erosion consolidation equations in terms of a perturbation parameter linked to the maximum expected internal erosion. A robust analytical solution was obtained via direct integration of equations at order zero and an adequate finite difference scheme that was applied at order one.
\end{abstract}

Keywords: Porous media, internal erosion, Darcy law, consolidation, asymptotic expansion

\section{Introduction}

Internal erosion is related to the migration of soil particles through the soil matrix by suffusion or piping. This phenomenon is generated by water seepage when the hydraulic gradient reaches a critical value. It starts as suffusion of soil fines that takes place inside the foundations of hydraulic retaining structures such embankment dams and levees, then progresses and reaches the advanced stage of piping. This last consists of regressive erosion which develops from downstream of seepage line towards upstream until forming a continuous pipe.

Internal erosion can lead to catastrophic failures of hydraulic infrastructures. This is aggravated by the fact no external sign is visible until its occurrence. Furthermore, a dam may breach only a few hours after evidence of piping. Understanding the early stages of internal erosion during the suffusion phase is of huge interest from the practical point of view. Predicting internal erosion can give the possibility to perform in better way health monitoring of hydraulic infrastructures through assessing active protection of these vital facilities.

Some significant recent advances have been made in deriving the physical laws that govern internal erosion [1], [2], [3] and [4]. In the proposed models, the soil is viewed as a three-phase continuous medium with the representative volume element consisting of solid particles, discharging fluid and fluidized grains extracted by erosion from soil skeleton [1]. Fluid flow induced erosion was recognized to be coupled with the poromechanical behaviour. Based on experimental results that had indicated that mass production of eroded particles tends to decrease over time, an erosion law had been suggested where the rate of fluidized grains production was assumed to be proportional to the hydraulic gradient discharge [4-7]. Under this form the equation of erosion was coupled to Darcy equation and thus to consolidation phenomenon taking place in the soil.

The previous internal erosion modelling was reappointed in this work. But, since focus is done on the early stage of erosion, the soil skeleton is assumed to deform elastically in the vicinity of the actually reached equilibrium point during the pre erosion stage. In addition, variations of soil porosity resulting from erosion are supposed to yield damage of soil Young's modulus according to the classical law of damage mechanics [8,9].

Considering the one-dimensional approximation of internal erosion in the special case of soil samples made from controlled mixed proportions of sand and clay, the equations governing the problem are developed. These are found to be coupled equations that include erosion, poro-elastic consolidation and transport of eroded 
particles. They are instable and their direct numerical integration through the standard finite element method has given rise to poor results [10]. In the context of fully coupled internal erosion and consolidation of soils, numerical difficulties were also observed while using the standard finite element method to integrate the problem [11]. These instabilities had taken the form of wiggles that had arisen in the case of high gradients conditions where the local field variables varied considerably.

In the present work, further physical simplifications are introduced to integrate internal erosion equations in a robust way. The internal erosion consolidation problem can be viewed like this to be the classical consolidation problem perturbed by porosity variations. This suggests performing asymptotic expansion of the obtained equations in terms of a scale parameter chosen to be the magnitude of porosity variations. Under these conditions, the problem is shown to have a closed form analytical solution that gives explicitly porosity time variations. Simulations are conducted after that in order to study the influence of factors such as soil permeability, soil resistance to erosion and hydraulic gradient magnitude on internal erosion.

\section{Materials and methods}

An erosion model is proposed here for the special case of a soil sample that consists of a mixture made from sand and clay where the clay phase is assumed to be erodible and erosion remains limited. The model is considered in the case of one dimensional approximation. Part of the equations is based on relevant previous works in this field such as [3] and [7]. New modifications of these equations are introduced. They consist of an extension of the erosion law and the consideration of damage resulting form erosion in the soil behaviour.

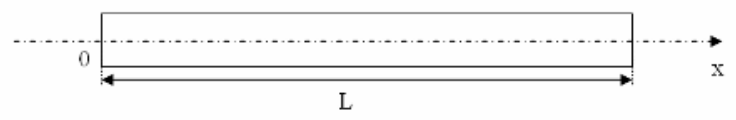

Fig. 1: Geometry of the soil sample

Within the framework of the three-phase continuum approach [1], it is assumed that the detached eroded particles move immediately at the velocity of adjacent water particles. This is only an approximation since in reality kinematics of fluidized grains is complex and their velocities are in general less than that of the fluid. The concept of Darcy velocity which represents a fraction of the true fluid particle speed and which is associated to the apparent percolation rate is used [12]. It is assumed furthermore that the whole clay grains that are extracted by the discharging water flow are added to the fluidized solid phase.

Assuming that density of eroded particles is equal to that of solids grains, one obtains by writing mass conservation the following equations

$\frac{\partial \mathrm{q}}{\partial \mathrm{x}}+(1-\varphi) \frac{\partial^{2} \mathrm{u}}{\partial \mathrm{x} \partial \mathrm{t}}-\frac{\partial \mathrm{u}}{\partial \mathrm{t}} \frac{\partial \varphi}{\partial \mathrm{x}}=0$

$$
\varphi \frac{\partial \mathrm{c}}{\partial \mathrm{t}}+\mathrm{q} \frac{\partial \mathrm{c}}{\partial \mathrm{x}}=(1-\mathrm{c})\left(\frac{\partial \varphi}{\partial \mathrm{t}}+\frac{\partial \mathrm{u}}{\partial \mathrm{t}} \frac{\partial \varphi}{\partial \mathrm{x}}-(1-\varphi) \frac{\partial^{2} \mathrm{u}}{\partial \mathrm{x} \partial \mathrm{t}}\right)
$$

where $\mathrm{x}$ is the axial coordinate, $\mathrm{t}$ the time, $\varphi$ is the soil porosity defined as the ratio of void volume over total volume, $\mathrm{c}$ the concentration of the fluidized solid defined as the ratio of eroded volume over void volume, $u$ the soil skeleton displacement and q the Darcy velocity .

The experimental law of Darcy gives water volume discharge that flows across the porous soil sample per unit time. Since in practice $\mathrm{c} \ll 1$ and the fluid phase density is almost equal to that of water, using the Kozeny- Carman law [7] enables to write Darcy law as

$q=-\frac{\mathrm{k}_{0} \varphi^{3}}{\mathrm{~g} \rho_{\mathrm{w}}(1-\varphi)^{2}} \frac{\partial \mathrm{p}}{\partial \mathrm{x}}$

where $\mathrm{k}_{0}$ is the initial soil permeability, $\mathrm{p}$ is the pore pressure, $\mathrm{k}$ the hydraulic permeability and $\mathrm{g}$ the constant of gravity and $\rho_{\mathrm{w}}$ water density.

Soil displacement is assumed to remain quasi-static. The stress state inside the soil sample is determined by considering Terzaghi principle which introduces the concept of effective stress [12]. According to this principle, the total stress filed is given by $\sigma=\sigma^{\prime}-p$ where $\sigma^{\prime}$ is the effective stress that governs soil behavior and $\mathrm{p}$ the pore pressure.

Erosion phenomenon can be viewed to be associated to a degradation mechanism that occurs inside the soil medium and which affects essentially the porosity. This last increases following grain detachment from the solid skeleton. As the purpose of this work is to predict the early stage of internal erosion, one may assume that the mechanical behaviour of the soil skeleton is elastic. This can be obtained from local linearization of soil constitutive equations around the actual equilibrium point. Local equilibrium of soil sample writes $\partial \sigma / \partial x=0$. It follows then from Hook's law and Terzaghi postulate that

$\frac{\partial}{\partial x}\left(E_{1}\left(1+\varphi_{0}-\varphi\right) \frac{\partial u}{\partial x}\right)=\frac{\partial p}{\partial x}$

with $E_{1}=\frac{E(1-v)}{(1+v)(1-2 v)}$

where $\mathrm{E}$ is the pre-erosion soil Young's modulus as measured for the initial porosity $\varphi_{0}$ and $v$ Poisson's coefficient.

Classical laws for internal erosion were proposed by putting either the erosion rate to be proportional to fluid discharge [4-6] or by putting the particle discharge to be proportional to porosity gradient [13]. The advantage of this last is that, for small eroded particle concentration, erosion resulted in a porosity diffusion law which was found to uncouple the porosity form the coupled set of equations describing soil consolidation, yielding a simple integration of equations. But, this erosion law was found to be insufficient to explain all the observed experimental 
results [13]. In the subsequent an extension of the erosion law that was formulated in [4] is proposed under the following form

$$
\frac{\partial \varphi}{\partial t}=\frac{\rho_{\mathrm{S}} \mathrm{k}_{0}}{\mathrm{~g} \rho_{\mathrm{w}} \tau_{\mathrm{er}}} \frac{\varphi^{3}}{(1-\varphi)^{2}}\left(1-\frac{\varphi}{\varphi_{\mathrm{c}}}\right)\left|\frac{\partial \mathrm{p}}{\partial \mathrm{x}}\right|+\frac{\partial^{2} \mathrm{u}}{\partial \mathrm{x} \partial \mathrm{t}}
$$

where $\rho_{\mathrm{s}}$ is the solid grains density, $\tau_{\mathrm{er}}$ is a soil parameter measuring soil resistance to erosion and $\varphi_{c}$ the maximal porosity that could be attained due to the fact that the soil skeleton contains a part which is not erodible.

Using equations (1) to (6), the following equation is derived

$$
\begin{aligned}
& \frac{\partial^{2} \mathrm{p}}{\partial \mathrm{x}^{2}}=\frac{1}{\mathrm{C}_{\mathrm{v}}(\varphi)} \frac{\partial \mathrm{p}}{\partial \mathrm{t}}+\frac{1}{\mathrm{C}_{\mathrm{v}}(\varphi)\left(1+\varphi_{0}-\varphi\right)} \frac{\partial \varphi}{\partial \mathrm{t}} \mathrm{p} \\
& -\frac{3-\varphi}{(1-\varphi) \varphi} \frac{\partial \mathrm{p}}{\partial \mathrm{x}} \frac{\partial \varphi}{\partial \mathrm{x}}-\frac{\mathrm{E}_{1}\left(1+\varphi_{0}-\varphi\right)}{\mathrm{C}_{\mathrm{v}}(\varphi)(1-\varphi)} \frac{\partial \mathrm{u}}{\partial \mathrm{t}} \frac{\partial \varphi}{\partial \mathrm{x}}
\end{aligned}
$$

with $C_{v}(\varphi)=\frac{k_{0} E_{1} \varphi^{3}\left(1+\varphi_{0}-\varphi\right)}{\rho_{w} g(1-\varphi)^{3}}$

Equations (4), (6) and (7) form a system of three independent equations having the three unknowns $u, \varphi$ and $\mathrm{p}$. When solution of these three equations is obtained, equations (1) and (2) can be used to compute concentration of the fluidized grains and Darcy velocity. After extensive investigation trying to integrate directly system of equations (4), (6) and (7) by means of the standard finite element method, numerical instabilities have always emerged yielding to systematic divergence of results. This is inherent to this kind of coupled equations because they are ill-conditioned as was recognized in [10,11] and [14].

Hence, asymptotic expansion technique is considered in the following in order to transform the erosion consolidation equations into a more stable form that is suitable for numerical integration.

Examining equation (7) one can notice that it consists of the classical consolidation equation that appears to be perturbed by erosion taking place inside the soil sample: variation of porosity $\varphi$. Assuming that the porosity is constant $\varphi=\varphi_{0}$, equation (7) yields the classical consolidation equation

$\frac{\partial^{2} \mathrm{p}}{\partial \mathrm{x}^{2}}=\frac{1}{\mathrm{C}_{\mathrm{v}}\left(\varphi_{0}\right)} \frac{\partial \mathrm{p}}{\partial \mathrm{t}}$

where $\mathrm{C}_{\mathrm{v}}\left(\varphi_{0}\right)$ is the classical consolidation coefficient.

For further details about consolidation theory based on Terzaghi theory [12] or the nonlinear theory, the reader can consult references [11] and [15].

The above remark invites us to choose as the scale parameter, that governs the perturbed consolidation problem associated to equations (4), (6) and (7), the following expression which is linked to the maximal porosity that could be reached $\varepsilon=1-\frac{\varphi_{0}}{\varphi_{\mathrm{c}}}$

Parameter $\varepsilon$ is equal to zero when there is no possibility of internal erosion inside the soil sample, that is $\varphi_{c}=\varphi_{0}$. In order to simplify further the model, the initial porosity is assumed to be uniform over the whole soil sample, thus the initial gradient of porosity vanishes and

$\frac{\partial \varphi_{0}}{\partial \mathrm{t}}=\frac{\partial \varphi_{0}}{\partial \mathrm{x}}=0$

As a first order approximation, the asymptotic expansion in terms of $\varepsilon$ is considered to be given by

$\mathrm{p}=\mathrm{p}_{0}+\varepsilon \mathrm{p}_{1} ; \quad \mathrm{u}=\mathrm{u}_{0}+\varepsilon \mathrm{u}_{1} ; \quad \varphi=\varphi_{0}+\varepsilon \varphi_{1}$

By substituting (12) into equations (4), (6) and (7), one obtains at orders 0 and 1 the following equations

$$
\begin{aligned}
& \frac{\partial \mathrm{u}_{0}}{\partial \mathrm{x}}=\frac{\mathrm{p}_{0}+\sigma_{0}}{\mathrm{E}_{1}} \\
& \frac{\partial \varphi_{0}}{\partial \mathrm{t}}=\frac{\partial^{2} \mathrm{u}_{0}}{\partial \mathrm{t} \partial \mathrm{x}} \\
& \frac{\partial^{2} \mathrm{p}_{0}}{\partial \mathrm{x}^{2}}=\frac{1}{\mathrm{C}_{\mathrm{v} 0}} \frac{\partial \mathrm{p}_{0}}{\partial \mathrm{t}}+\frac{1}{\mathrm{C}_{\mathrm{v} 0}} \frac{\partial \sigma_{0}}{\partial \mathrm{t}} \\
& \frac{\partial \mathrm{u}_{1}}{\partial \mathrm{x}}=\frac{1}{\mathrm{E}_{1}}\left(\left(\mathrm{p}_{0}+\sigma_{0}\right) \varphi_{1}+\mathrm{p}_{1}\right) \\
& \frac{\partial \varphi_{1}}{\partial \mathrm{t}}=\frac{\rho_{\mathrm{S}} \mathrm{K}_{0}}{\eta_{\mathrm{w}} \tau_{\mathrm{er}}}\left\langle-\left(\frac{\varphi_{0}-\varphi_{1}}{\varphi_{0}}\right)\left(\frac{\partial \mathrm{p}_{0}}{\partial \mathrm{x}}+\frac{\eta_{\mathrm{w}}}{\mathrm{K}_{0}} \mathrm{q}_{\mathrm{er}}\right)\right\rangle+\frac{\partial^{2} \mathrm{u}_{1}}{\partial \mathrm{t} \partial \mathrm{x}} \\
& \frac{\partial^{2} \mathrm{p}_{1}}{\partial \mathrm{x}^{2}}=\frac{1}{\mathrm{C}_{\mathrm{v} 0}}\left(\frac{\partial \mathrm{p}_{1}}{\partial \mathrm{t}}-\frac{\varphi_{1}\left(3-\varphi_{0}+\varphi_{0}^{2}\right)}{\varphi_{0}\left(1-\varphi_{0}\right)} \frac{\partial \mathrm{p}_{0}}{\partial \mathrm{t}}\right) \\
& -\frac{1}{\mathrm{C}_{\mathrm{v} 0}} \frac{\varphi_{1}\left(3-\varphi_{0}+\varphi_{0}^{2}\right)}{\varphi_{0}\left(1-\varphi_{0}\right)} \frac{\partial \sigma_{0}}{\partial \mathrm{t}}+\frac{\mathrm{p}_{0}+\sigma_{0}}{\mathrm{C}_{\mathrm{v} 0}} \frac{\partial \varphi_{1}}{\partial \mathrm{t}} \\
& +\left(\frac{\eta_{\mathrm{w}}}{\mathrm{K}_{0}} \frac{\partial \mathrm{u}_{0}}{\partial \mathrm{t}}-\frac{3-\varphi_{0}}{\varphi_{0}\left(1-\varphi_{0}\right)} \frac{\partial \mathrm{p}_{0}}{\partial \mathrm{x}}\right) \frac{\partial \varphi_{1}}{\partial \mathrm{x}}
\end{aligned}
$$

\section{Results and discussion}

Solution of equations (13) to (18) is considered when the left hand side of the soil sample, Fig.1, is suddenly subjected to an increase of pressure from the initial value $\mathrm{p}_{\mathrm{ei}}$ to the final fixed value $\mathrm{p}_{\mathrm{e}}$, while the pressure in the right hand side is maintained at the vlaue $\mathrm{p}_{\mathrm{si}}$. The initial conditions associated to equations (13) to (17) are considered under the following form:

$$
\begin{aligned}
& \sigma_{0}(\mathrm{x}, \mathrm{t}=0)=\sigma_{0}, \quad \varphi_{0}(\mathrm{x}, \mathrm{t}=0)=\varphi_{\mathrm{i}}, \quad \varphi_{1}(\mathrm{x}, \mathrm{t}=0)=0 ; \\
& \mathrm{p}_{0}(\mathrm{x}, \mathrm{t}=0)=\mathrm{p}_{\mathrm{ei}}+\mathrm{x}\left(\mathrm{p}_{\mathrm{si}}-\mathrm{p}_{\mathrm{ei}}\right) / \mathrm{L}, \quad \varphi_{1}(\mathrm{x}, \mathrm{t}=0)=0 ; \\
& \mathrm{p}_{1}(\mathrm{x}, \mathrm{t}=0)=0 .
\end{aligned}
$$

The boundary conditions applying at the left hand extremity $\mathrm{x}=0$ which correspond to a given pressure 
and vanishing strain and pressure perturbation gradient are:

$\sigma_{0}(x=0, t)=\sigma_{0} ; p_{0}(x=0, t)=p_{e} ; p_{1}(x=0, t)=0$.

The boundary conditions applying at right extremity $\mathrm{x}=\mathrm{L}$ that correspond to given pressure and vanishing displacement and pressure perturbation gradient are:

$\mathrm{u}_{0}(\mathrm{x}=\mathrm{L}, \mathrm{t})=0 ; \quad \mathrm{p}_{0}(\mathrm{x}=\mathrm{L}, \mathrm{t})=\mathrm{p}_{\mathrm{si}} ; \quad \mathrm{u}_{1}(\mathrm{x}=\mathrm{L}, \mathrm{t})=0 ;$ $\mathrm{p}_{1}(\mathrm{x}=\mathrm{L}, \mathrm{t})=0$.

Let's consider a soil sample occupying a cylindrical domain having length $\mathrm{L}=2 \mathrm{~m}$, Fig. 1 . The soil is assumed to be at rest under static equilibrium condition with a uniform initial porosity $\varphi_{\mathrm{i}}=0.35$. At the instant $\mathrm{t}=0$ a pressure increment of magnitude $\Delta \mathrm{p}_{\mathrm{e}}$ is applied at the left side extremity while $\mathrm{p}_{\mathrm{si}}=0$. The other soil data are: $\rho_{\mathrm{w}}=1000 \mathrm{~kg} \cdot \mathrm{m}^{-3}, \quad \rho_{\mathrm{s}}=2650 \mathrm{~kg} \cdot \mathrm{m}^{-3}$, $\mathrm{E}_{0}=2 \times 10^{8} \mathrm{~Pa}, v=0.25, \varphi_{\mathrm{c}}=0.45 . \Delta \mathrm{p}_{\mathrm{e}}=5 \times 10^{4} \mathrm{~Pa}$, $\mathrm{k}_{0}=10^{-2} \mathrm{~m} \cdot \mathrm{s}^{-1}$ $\mathrm{q}_{\mathrm{er}}=5 \times 10^{-2} \mathrm{~m} \cdot \mathrm{s}^{-1}$ and $\tau_{\mathrm{er}}=10 \mathrm{~kg} \cdot \mathrm{m}^{-2}$.

Fig. 2 shows the obtained porosity as function of space and time. Porosity increases at the inlet extremity, reaches a maximum and then decreases to the right.

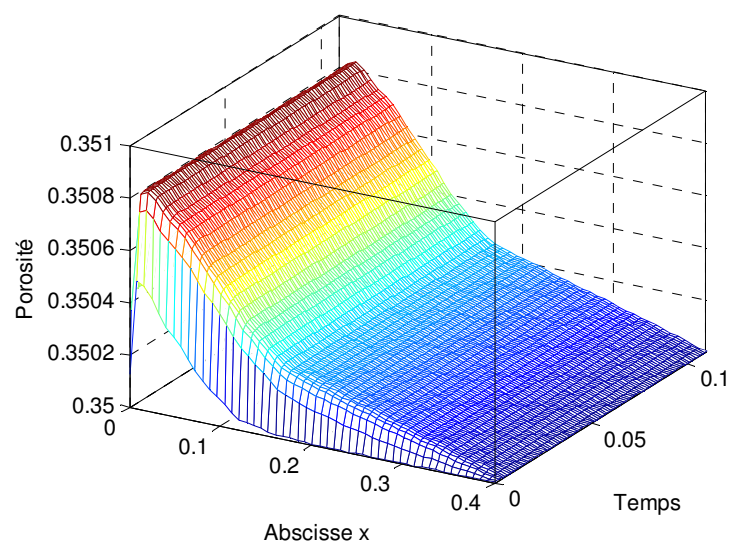

Fig.2: Spatial-temporal distribution of porosity

\section{Conclusion}

Analytical modelling of erosion phenomenon taking place in a soil sample consisting of sand and clay mixture was performed under the assumption of one dimensional approximation. Asymptotic expansion technique was used for that and the maximum potential porosity was chosen as the scale factor. Closed form solution has been obtained for soil porosity in terms of the intervening factors. This enables stabilizing integration of the coupled erosion-consolidation equations.

\section{References}

1. Vardoulakis I., M. Stavropoulou, P. Papanastasiou. Hydromechanical aspects of sand production problem, Transport Porous Media 22, 225-244, 1996.
2. Vardoulakis I. Fluidisation in artesian flow conditions: Hydromechanically stable granular media. Géotechnique, 54(2): 117-130, 2004.

3. Wan R.G., Wang J. Analysis of sand production in unconsolidated oil sand using a coupled erosional-stressdeformation model. Journal of Canadian Petroleum Technology, 43(2): 47-52, 2004.

4. Stavropoulou M., Papanastasiou P., Vardoulakis I. Coupled wellbore erosion and stability analysis. International Journal for Numerical and analytical Methods in Geomechanics, 22: 749-769, 1998.

5. Sakthivadivel R., Irmay S. A review of fitration theories, Technical Report of Hydraulic Engineering Laboratory, 15-4, University of Berkeley, 1966.

6. Vardoulakis I., Stavropoulou M., Papanastasiou P. Hydromechanical aspects of sand production problem. Transport in Porous Media, 22, 225-244, 1996.

7. Papamichos E. Failure in rocks, Hydro-mechanical coupling for erosion. Revue Française de Génie-Civil, 8: 709-734, 2004.

8. Lemaitre J. How to use damage mechanics. Nuclear Engineering and Design 80 (2), 233-245, 1984

9. Kachanov L. Introduction to Continuum Damage Mechanics. Martinus Nijhoff Publishers, Netherlands, 148pp, 1986.

10. Chen R.P., Zhou W.H., Wang H.Z., Chen Y.M. Onedimensional nonlinear consolidation of multi-layered soil by differential quadrature method. Computers and Geotechnics 32, 358-369, 2005.

11. Wang J., Wan R.G. Computation of sand fluidization phenomena using stabilized finite elements. Finite Elements in Analysis and Design 40, 1681-1699, 2004.

12. Terzaghi K., Peck R.B., Mesri G. Soil Mechanics in Engineering Practice. Wiley-Interscience, 1996.

13. Papamichos E., Vardoulakis I. Sand erosion with a porosity diffusion law. Comp. and Struc., 32:47-58, 2005. 14. Mira P., Pastor M., Li T., Liu X. A new stabilized enhanced strain element with equal order of interpolation for soil consolidation problems. Comput. Methods Appl. Mech. Engrg. 192, 4257-4277.

15. Cornetti P., Battaglio M. Nonlinear consolidation of soil modelling and solution techniques. Mathl. Comput. Modelling 20(7),1-12, 1994. 